\title{
Soil Nutrient Status in Fodder Growing Areas of Southern and Hilly Districts of Tamil Nadu, India
}

\author{
M. Suganthi*, Karu Pasupathi and D. Balasubramaniyam
}

Research Institute in Animal Sciences, TANUVAS, Chennai -51, India

*Corresponding author

\section{Keywords}

Organic carbon,

Potassium,

Nitrogen, fodder

crops, Nutrients

Article Info

Accepted:

20 June 2020

Available Online:

10 July 2020

\begin{abstract}
A B S T R A C T
In the present research work, studies on soil nutrient status assessed by carrying out nutrient analysis such as Nitrogen Phosphorus, Potassium and organic matter content in the soils. physical parameters such as PH and EC were also reported. In India most of the fodder growing area is with poor soils and lack of proper maintenance. Hence the present study focuses on to assess the soil nutrient status in fodder growing districts such as Madurai Pudukottai Tirunelveli and Nilgiris and Madurai areas of Tamilnadu. The soils are basic and nitrogen content is low in all the southern parts in least and lower level except Tirunelveli which recorded mediumin Nitrogen content.( $121.27 \pm 14.05 \mathrm{~kg} / \mathrm{acre})$ and the phosphorus content is medium in all districts except Nilgiris which recorded higher level of phosphorus and the potassium content is medium in all districts except Tirunelveli . The nitrogen content is deficient in all the districts, Phosphrous and potassium content is ranges from medium to higher level in all the southern districts. The organic carbon content is also lower in all the districts of southern district except Nilgiris. Top dressing of nitrogenous fertilizer, application of well decomposed farm yard manure and application of phosphorus as a basal dose are the recommendations given to the farmers. Application of biofertilizer also helps to reduce the immobilization of nutrients which corrects the deficiency
\end{abstract}

\section{Introduction}

The availability of fodder is one of the limiting factors in animal husbandry. Organic husbandry should be mainly based on the fodder produced on the farm itself. As is the case with humans, there is a direct link between the food and the health of the animals. Fodder based cheaper feeding strategies are required to reduce the cost of quality livestock product as the feed alone constitutes $70 \%$ of the milk production cost. There is tremendous pressure of livestock on available total feed and fodder, as land available for fodder production has been decreasing. At present, the country faces a net deficit of $61.1 \%$ green fodder, $21.9 \%$ dry crop residues and $64 \%$ feeds.

At the current level of growth in forage resources, there will be $66 \%$ deficit in green fodder and $25 \%$ deficit in dry fodder. Green forage supply situation has to grow at $3.2 \%$. Availability of green fodder decides the livestock industry growth and development. Land allocation to cultivation of green fodder 
crops is limited and has hardly ever exceeded 5 per cent of the gross cropped area (GoI, 2009). The deficit gap of availability vis-à-vis the requirement of green fodder is huge at 665.80 million MT $(62.76 \%)$ and 138 million MT $(23.46 \%)$ for dry fodder. The deficit of concentrates also found to be more than 30 percent. Birthal and Jha (2005) have found feed scarcity as the main limiting factor to improve livestock productivity. Therefore, it is important to put more emphasis on fodder development programmes for augmenting fodder /feed supply.

Growing of quality fodder which depends on the soil nutrient status. Growing fodder crops in poor soils and lack of proper maintenance of pasture land which is one of the major challenge in adequate supply of quality feed and fodder. one of the major constraints in enhancing fodder production as well as productivity is lack of inadequate production and availability of quality seed yielding varieties of fodder crops (Suganthi et al., 2018). Several constraints in fodder production is lack of seed material, poor quality soils, inadequate fertilizer application, moisture scarcity, improper timing of sowing and inadequate facilities to transport and store the forage.

Quality Soil is the main deciding factor which helps to asses the yield of the crop. Hence to assess the soil nutrient status in Tamil Nadu "TNSLURB sponsored soil testing programme" was carried out in Southern districts such as Madurai, Pudukottai, Tirunelveli and Nilgiris Districts.

Apart from fodder crops major crops observed are Groundnuts, sugarcane, cereals, millets and pulses. Soil type of these districts are Red soil, black cotton soil, loamy soil, and late rite soil and sandy soil. This study focuses mainly on the nutrient status of the soil and recommendations.

\section{Materials and Methods}

Farmers holding a minimum of 50 cents of land and rearing livestock were selected as beneficiaries in this scheme. A total of fifty farmers in each districts were selected. Soil samples were collected as per the sampling technique. The fields were divided into different homogenous units based on the visual observation and farmers experience and the surface litter was removed from the sampling spot. A plough depth of $15 \mathrm{~cm}$ was made to draw soil sample and 10 samples were made from each sampling unit. Thick slides of soil from top to bottom of the exposed face of the ' $\mathrm{V}$ ' shaped cut were collected. The pooled soil sample about $500 \mathrm{~g}$ was taken in duplicate from selected 400 livestock farmer's field. $\mathrm{N}, \mathrm{P}, \mathrm{K}, \mathrm{pH}$ and Electrical conductivity of the soil were estimated.

\section{Results and Discussion}

Various kinds of stress affect the crop plants especially the fodder crops which grown in poor degraded soil (Suganthi et al., 2018). pH and Electrical conductivity are the two main factor which influences the nutrient uptake by the crop. Hence, to overcome the nutrient stress $\mathrm{pH}$ and Electrical conductivity of the soil should in optimum. Most of the fodder growing soils of southern district are slightly alkaline $(47.5 \%)$.

Lower availability of micro and macro nutrients might be due to the alkalinity of the soil. Around 30 percent of the soil is neutral in $\mathrm{pH}$ only. 22.5 percent of the soil is acidic in nature. Hence fodder crop may be recommended in acid soil to correct the $\mathrm{pH}$ to normal. Low nitrogen status was observed in all fodder growing area of southern district. This might be due to low amount of organic carbon in the soil. The results were evident from Table 1. 
Table.1 Assessment of soil chemical characteristics

\begin{tabular}{|l|c|c|c|c|c|}
\hline \multicolumn{1}{|c|}{ Parameters } & Range & Mean & & & \\
\hline pH & $4.1-9.43$ & 6.77 & & & \\
\hline EC & $0.05-0.93$ & 0.49 & & & \\
\hline Macronutrients & Range & Mean (kg/ha) & Low (\%) & $\begin{array}{l}\text { Medium } \\
(\mathbf{\%})\end{array}$ & High (\%) \\
\hline Nitrogen (kg/ha) & $4.67-250$ & 127.3 & 82.5 & 14.5 & 3.0 \\
\hline Phosphorus (kg/ha) & $0.13-36.85$ & 18.5 & 44 & 55.5 & 0.5 \\
\hline Potassium (kg/ha) & $23.4-396.7$ & 210.1 & 19.5 & 40.5 & 40.0 \\
\hline Organic carbon (\%) & $0.02-1.2$ & 0.61 & 51.5 & 34.0 & 14.5 \\
\hline
\end{tabular}

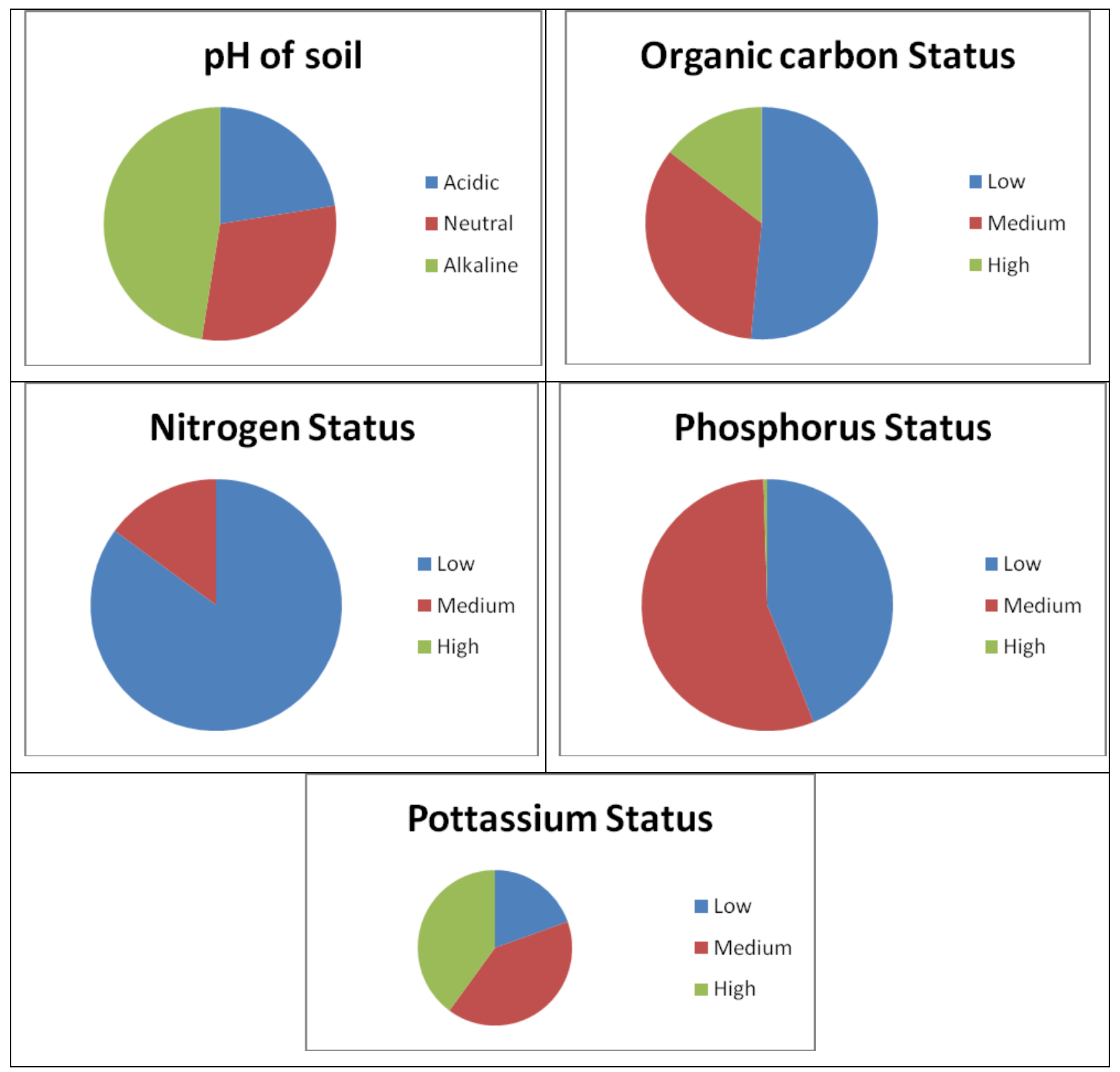

Fig.1 Southern districts of Tamilnadu 
Similar result was also reported by Verma et $a l .$, (1980). Nitrogen level ranges from 4.67 to $250 \mathrm{~kg} / \mathrm{ha}$ which is low as that of average $(250 \mathrm{~kg} / \mathrm{ha})$. Forty four percent of fodder growing area is low in phophorus and 55 percent area is medium in status. It might be due to the over exploitation of nitrogen and lower solubilisation of $\mathrm{P}$ in soil by the fodder crop.

Indian soils are rich in potassium which is evident from the study. Nearly $40.0 \%$ of soils are high and $34.0 \%$ are medium in potassium. Whereas organic carbon content is lower in $51.5 \%$ of the soil in southern districts of Tamilnadu. Soils with lower organic carbon can generally provide a lower reserve of macro elements (Vijayakumar et $a l ., 2011)$. The very low OC content of these soils may be attributed to the poor vegetation . It may be attributed by the lower rate of organic manure application to the fodder growing area.

Since Cumbu Napier hybrid is perennial crop $10 \mathrm{t} / \mathrm{ac}$ of FYM is recommended. Due to unavailability and lack of awareness, the farmers are not applying the recommended quantity of FYM and other inorganic fertilizer. Hence recommendation is given for top dressing of Nitrogenous fertilizer or composted FYM application during every establishment of the crop. Inclusion of green manure crops and cover crops in the cropping system would be an option to increase the nutrient available status of the soils in The Nilgiris, Madurai, Pudukkottai and Tirunelveli Districts.
The results shows that the availability of nutrients in the soil is controlled by important characteristics of soil properties such as $\mathrm{pH}$, EC and OC. improve the nutrient status and other physical character of soil will help to correct the deficiency of future fodder growing area. Thus we can improve the fodder production as well.

\section{References}

Birthal, P.S and Jha, A.K. 2005. Economic losses due to various constraints in dairy production in India. Indian Journal of Animal Sciences, 75: 1476-1480.

GoI .2009. Year-wise Area under Crops - All India.Available at: http://dacnet.nic.in/eands/LUS-2006-07/ Summary/tb3.13.pdf.

Suganthi, M., D. Balasubramanyam, S.Gunasekaran and H.Gopi.2018. Survey report on soil nutrient status in fodder growing areas of Northern Districts of Tamil Nadu. Multilogic in Science. vol. viii, Special issue (d) August 2018. ISSN. 2277-7601

Verma, L.P., B.R.Tripath and D.P.Sharma.1980. Organic Carbon as on index to assess the nitrogen status of the soil. J. Indian.Soc. Soil Sci. 28: 138140.

Vijayakumar.R, A. Arokiaraj and P. Martin Deva Prasath, 2011. Nutrients strength and their relationship with soil properties of natural disaster proned coastal soils. J. Chem. Pharm. Res., 3(3):87-92.

\section{How to cite this article:}

Suganthi. M., Karu Pasupathi and Balasubramaniyam. D. 2020. Soil Nutrient Status in Fodder Growing Areas of Southern and Hilly Districts of Tamil Nadu, India. Int.J.Curr.Microbiol.App.Sci. 9(07): 4069-4072. doi: https://doi.org/10.20546/ijcmas.2020.907.477 